\title{
Assessment of Corrosion in Retrieved Spine Implants
}

\author{
V. C. Panagiotopoulou ${ }^{\mathrm{a}, \mathrm{b}}$, H.S. Hothi ${ }^{\mathrm{a}}$, H. Anwar ${ }^{\mathrm{b}}$, S. Molloy ${ }^{\mathrm{b}}$, H. Noordeen ${ }^{\mathrm{b}}$, \\ K. Rezajooi ${ }^{\text {b }}$ J. Sutcliffe ${ }^{\mathrm{c}}$, J. Skinner ${ }^{\mathrm{a}, \mathrm{b}}$, A. Hart ${ }^{\mathrm{a}, \mathrm{b}}$
}

\begin{abstract}
a. Institute of Orthopaedics and Musculoskeletal Science, University College London
b. The Royal National Orthopaedic Hospital, Stanmore, United Kingdom

c. The London Spine Clinic, London, United Kingdom
\end{abstract}

Corresponding Author:

Vasiliki C. Panagiotopoulou

Institute of Orthopaedics and Musculoskeletal Science (University College London)

Royal National Orthopaedic Hospital

Brockley Hill

Stanmore, Middlesex

HA7 4LP

United Kingdom

Phone: +44 (0) 2089095825

Fax: $\quad+44(0) 2089548560$

Email: v.panagiotopoulou@ucl.ac.uk

We declare that all authors listed have participated in the research and that this article has not been submitted elsewhere. We confirm that all investigations were conducted in conformity with ethical principles of research, that informed consent for participation in the study was obtained and that institutional approval of the human protocol for this investigation was obtained. Two authors received funding from the British Orthopaedic Association through an industry consortium of nine manufacturers: DePuy International Ltd, Zimmer GmbH, Smith \& Nephew UK Ltd, Biomet UK Ltd, JRI Ltd, Finsbury Orthopaedics Ltd, Corin Group PLC, Mathys Orthopaedics Ltd, and Stryker UK Ltd. 


\begin{abstract}
Recently the use of dissimilar metals in spine instrumentation has increased, especially in the case of adult deformities, where rods made from Cobalt Chrome alloys $(\mathrm{CoCr})$ are used with Titanium (Ti) screws. The use of dissimilar metals increases the risk of galvanic corrosion and patients have required revision spine surgery due to severe metallosis that may have been caused by corrosion.
\end{abstract}

We aimed to assess the presence of corrosion in spine implant retrievals from constructs with two types of material combinations: similar (Ti/Ti) and dissimilar $(\mathrm{CoCr} / \mathrm{Ti})$. First we devised a grading score for corrosion of the rod-fixture junctions. Secondly, we applied this score to a collection of retrieved spine implants.

Our proposed corrosion grading score was proven reliable (kappa $>0.7$ ). We found no significant difference in the scores between $4 \mathrm{CoCr}$ and $11 \mathrm{Ti}$ rods $(\mathrm{p}=0.0642)$. There was no indication that time of implantation had an effect on the corrosion score $(p=0.9361)$.

We recommend surgeons avoid using implants designs with dissimilar metals to reduce the risk of corrosion whilst a larger scale study of retrieved spine implants is conducted. Future studies can now use our scoring system for spine implant corrosion.

Keywords: Corrosion; Spinal Implant; Cobalt-Chromium (alloys); Titanium (alloys); Implant retrieval

Running head: Assessment of Corrosion in Retrieved Spine Implants 


\section{INTRODUCTION}

Approximately 500,000 surgical procedures per year are performed for spine instrumentation in USA (1), exceeding hip replacement surgeries by 100,000 (2). However, research in retrieval analysis of spine instrumentation is surprisingly underdeveloped compared to the research of hip retrievals (3-5).

Research on corrosion of orthopaedic implants required grading scores for: 1) corrosion on the taper interfaces (6) and the stem surfaces (7) of hip implants; and 2) wear of the polyethylene of knee replacements (8). In spine instrumentation, only one grading score exists for fretting and crevice corrosion at the screw-rod junctions, but it applies only for stainless steel constructs (9). The use of dissimilar metals is common in spine surgery to take advantage of the physical and mechanical properties of different materials (10). However, there are recent concerns raised due to corrosion and wear $(5,11-17)$ and tissue reactions such as metallosis $(13,14,18)$. In the case of instrumentation that uses dissimilar metals, only preclinical testing has been performed (19) and neither post market surveillance studies using blood metal ions, nor implant retrieval studies.

This is the first retrieval study of comparing similar and dissimilar constructs at the rod-fixing junctions, focusing both on the surface of the rod and the surface of the rest of the instrumentation.

Our aim was to better understand the clinical significance of spine implants that use dissimilar metals. Our objectives were, first to develop a visual grading method for corrosion severity, secondly correlate surface damage on rods to screws, nuts, hooks and connectors; and thirdly relate corrosion findings to clinical and implant data. 


\section{MATERIALS \& METHODS}

This is a study of retrieved spine implants from 7 patients and 2 hospitals. We included rods, screws, set screws, hooks and connectors from six different manufacturers (DePuy Synthes, Globus, K2M, Medtronic, Orthofix and Stryker).

\section{Patients}

The cohort was composed of 4 females and 3 males with a median age of 32 (minimum 16maximum 64) years at primary with a median time of implantation of 12.5 months (minimum 4 - maximum 68) (see Table 1). Patients were revised for infection, pain, fracture and loosening of screws, correction of kyphosis and prevention of fusion.

\section{Macroscopic Inspection}

All rods were visually assessed for signs of discoloration and/ or scratching on the contact areas between (1) rods and screws; (2) rods and nuts; (3) rods and hooks; (4) rods and connectors. The same applied for the contact surfaces on the screws, setscrews, hooks and connectors. Details about the number of components and contact areas can be found in Table 2 .

\section{Microscopic Inspection}

Optical microscopy was performed on all components for signs of fretting, pitting and/ or corrosion using a Keyence VHX-700F series (Keyence Co., Japan). The magnification ranged from 20x-200x according to the inspected component.

\section{Scanning Electron Microscope (SEM)}

We used Scanning Electron Microscope (Hitachi S-3400 N) to determine surface changes on the areas of interest, especially to find signs of fretting and pitting on the contact areas on both rods and the rest of the components. 


\section{Energy Dispersive X-ray Spectroscope (EDX)}

In combination with SEM, we performed elemental analysis using Energy Dispersive X-ray Spectroscope (Oxford Instruments) at a working distance of $10 \mathrm{~mm}$, to determine whether the black debris seeing on the components are either biological deposits or corrosion products.

\section{Creation and Evaluation of grading score}

After performing macroscopic and microscopic inspection in all contact areas between the components we combined the findings in different groups. These groups served as a baseline for the proposed grading score for rods (see Figure 2) and for the adaptation of the score proposed for the tapers of hip replacement by Goldberg (see Figure 3). For the evaluation of the objectivity of the grading scores, all components were scored by two independent examiners with expertise on corrosion of implants. The scores were then compared for any statistical differences.

\section{Statistical Analysis}

Statistical analysis, using SPSS software, was performed to investigate (1) any significant difference or trends between the scores for $\mathrm{CoCr}$ rods versus the scores for Ti rods; (2) any correlation between score severity and time of implantation; (3) the objectivity and repeatability of the proposed grading score systems; (4) correlation between the score of the rod and the score of the screws, setscrews, hooks and connectors. 


\section{RESULTS}

\section{Macroscopic Inspection and Grading - Rods}

From the macroscopic inspection of the spine rods, we noticed four main trends on the surfaces of the rods: (1) no visible corrosion and/or fretting; (2) light discoloration (affecting less than $30 \%$ of the junction point) but without presence of pits or scratching; (3) moderate discoloration (affecting more than $30 \%$ of the junction point ), usually accompanied by the presence of some pits, scratches and/or black debris; (4) severe discoloration (affecting more than $50 \%$ of the junction point), accompanied by pits, scratching and/or black debris. Using these observations, we composed a visual grading score for the effect of screws, setscrews, hooks and connectors on the surface of spinal rods (see Figure 1 for score and criteria).

Table 3 includes the number of junctions that share the same score per material combination. Only $5 \%$ of junctions on the CoCr rods showed no evidence of surface damage. $46 \%$ of the CoCr rod junctions were discolored, but with no evidence of scratching, pits or black debris. We found that $44 \%$ of junctions had evidence of moderate discoloration and some scratching, pits or black debris, while $5 \%$ of the $\mathrm{CoCr} / \mathrm{Ti}$ junctions had the highest corrosion score (4), with severe discoloration and/or increased presence of scratching, pits or black debris. For the Ti rods, more than half of the junctions (67\%) were discolored only (no scratching, pitting or black debris), while the rest of the junctions were moderately discolored (33\%), with scratching, pits or black debris. No junctions on Ti rods were severely damaged (Grade 4).

In cases of junction scoring, where the percentage of discoloration resulted in a score different that the one that the percentage of surface marks proposed, the junctions were scored according to the severity of scratching, pitting and black debris.

\section{Macroscopic Inspection and Grading - Fixtures}


The macroscopic inspection of the contact areas of the rest of the components revealed similarities with the assessment of corrosion at the taper junctions of hip replacements. Thus, we adopted the corrosion score proposed from Goldberg et al. (6) for the visual evaluation of the contact areas on screws, setscrews, hooks and connectors (see Figure 3).

From the macroscopic grading of the retrieved screws, setscrews, hooks and connectors by first examiner (see Table 4 ), the majority of Ti components attached to $\mathrm{CoCr}$ rods $(88 \%)$ were either lightly or moderately discolored, with half of them having signs of black debris too. $6 \%$ of components were found with no apparent signs of damage, while only $6 \%$ had severe discoloration and excess amount of black debris. In the case of using similar materials, most of the $\mathrm{Ti}$ components $(48 \%)$ were moderately damaged with less than $30 \%$ of their surface discolored but no black debris, scratching and pits. Rest of the Ti fixtures had no black debris, with $40 \%$ being slightly discoloured and $12 \%$ showed no signs of discoloration.(20)

\section{Microscopic Inspection and Grading - Rods}

From the microscopic inspection of the rods, we found that the more severe the visual score, the more severe signs of fretting and pitting were present under the microscope. In the case of CoCr, Grade 1 was accompanied with initial marks of intergranular corrosion. Grade 2 and Grade 3 shared signs of fretting and pitting, as well as severe signs of intergranular corrosion The severity of fretting and pitting escalated with the severity of visual scoring grade. On the Ti rods, Grade 1 showed no signs of damage, while fretting and pitting was present in Grades 2 and 3. The higher the grade of the junction, the more fretting and pitting was observed under the microscope.

\section{Microscopic Inspection and Grading-Fixtures}


In all Ti components, microscopic inspection of grade 1 showed no signs of fretting or pitting. In components scored as grade 2, fretting was present, while in grades 3 and 4 , severe fretting was combined with some level of pitting.

\section{Scanning Electron Microscope and Grading - Rods}

Similarly, as the microscopic inspection, SEM revealed that the severity of the visual score was accompanied by the severity of fretting, pitting and presence of black debris. As seen in Figure 2, in Grade 1 for $\mathrm{CoCr}$ rods there is presence of intergranular corrosion initiation, although not visible during macroscopic inspection. For grades higher than 2, fretting and pitting are present. The more severe the fretting and pitting, the higher the grade. Black debris were also found while performing SEM.

\section{Scanning Electron Microscope and Grading - Fixtures}

We performed SEM on Ti components from both $\mathrm{CoCr} / \mathrm{Ti}$ constructs and $\mathrm{Ti} / \mathrm{Ti}$ constructs. Fretting and pitting corrosion were present on moderately damaged fixtures, while fixtures with score 1 showed no significant signs of fretting (see Figure 3). In fixtures with grade 4, a large surface of the contact area was covered with black debris.

\section{Energy Dispersive X-ray Spectroscope and Grading - Rods}

On the junctions of $\mathrm{CoCr}$ rods, elemental analysis on the black debris revealed transfer from the Ti components to the CoCr rods. The severity of the grade was reflected on the presence of oxygen, as well as titanium, aluminium and vanadium elements from the Ti components. Corrosion debris also included sulphur and phosphorus.

On the contrary, black debris on the junctions of Ti rods were of biological origin, since the elemental composition revealed potassium, calcium, sodium, chloride, iron and oxygen among the elements detected. 
Comparing EDX analysis data between CoCr rods and Ti rods, the amount of oxygen was increased on the CoCr rods ( $27 \%$ on average) compared to Ti rods ( $17 \%$ on average). However, we were not able to confirm whether galvanic coupling accelerated the corrosion process.

\section{Energy Dispersive X-ray Spectroscope and Grading - Fixture}

Elemental composition analysis on $\mathrm{Ti}$ components from both $\mathrm{CoCr} / \mathrm{Ti}$ and $\mathrm{Ti} / \mathrm{Ti}$ constructs revealed that black debris was mostly biological, rather than corrosive debris. This was suggested by the presence of oxygen with sodium, potassium, chloride and iron. No transfer from $\mathrm{CoCr}$ rods to Ti fixtures was observed.

\section{Evaluation of Corrosion Grading Score - Rods}

All rod junctions were evaluated independently by two examiners, expert in corrosion of medical devices. We then performed kappa analysis in order to assess the agreement of the two examiners, and thus determine the repeatability and objectivity of the proposed score for corrosion on rod junctions. Analysis in SPSS revealed that kappa was 0.737 for the scoring of $\mathrm{CoCr}$ rods, while in the case of Ti rods kappa was 0.775 . Both values are described as substantial agreement between the two examiners in grading the junctions of the rods.

\section{Evaluation of Corrosion Grading Score - Fixtures}

Same principal was applied to the scoring of the fixtures. Once agreed to the adaptation of the already published Goldberg score to the contact areas of the fixtures, the two examiners scored the areas independently. SPSS analysis revealed that the kappa coefficient was 0.753 suggesting substantial agreement between the examiners.

\section{Statistical Analysis}

Using SPSS software, we performed statistical analysis in order to find any significant differences between the use of different materials and the time of implantation. We calculated 
the mean value for all junctions per rod and the mean value for all contact areas of fixtures per patients (see Table 5 for the values). Using the ANOVA non-parametric test, we found no significant difference for the corrosion scores between using similar or dissimilar materials $(\mathrm{p}=0.0642)$. We also tested whether there is correlation between time of implantation and corrosion score of the rod junctions, but the non-parametric t-test showed no significant difference $(\mathrm{p}=0.9361)$. Comparison of the scores between fixtures from different patients, revealed no significant difference when correlated with time of implantation. 


\section{DISCUSSION}

In this study, we describe grading scores and criteria for the assessment of fretting, pitting and corrosion on rod junctions and contact areas of fixtures used in spinal implants. Statistical kappa analysis showed the scoring systems to be reproducible between different examiners. These scoring methods may now be used in future studies investigating retrieved spinal implants.

Our findings suggest that there is no significant difference in the severity of corrosion between the $\mathrm{CoCr}$ and Ti rod junctions investigated in this study. It is of note however that only the CoCr components showed evidence of severe corrosion (grade 4), in the case of rods revised for pain, while intra-operatively metallosis was noted. This difference between the two metal alloy combinations was however only marginally insignificant $(\mathrm{p}=0.0642)$.

Comparing the results from the forensic analysis of the different materials, similar macroscopic patterns between the two different types of constructs with the same score resulted in similar trends during the microscopic inspection, highlighting the similarities due the implantation damage regardless the material. The use of different materials in spine instrumentation selfindicates the importance of a universal score, which can be used regardless material combination or material consistency. Based on the hip retrieval research, the widely-used Goldberg score (6) has been established by comparing fretting and corrosion on both retrievals made of CoCr and Ti alloys.

We did not find a significant correlation between time of implantation and overall rod score, suggesting that some indentations and marks on the rod junctions might occur during the fixing process of the implantation rather than during use in situ. The mean corrosion scores for $\mathrm{CoCr}$ rods revised for pain were higher than the mean corrosion scores for $\mathrm{CoCr}$ rods revised for infection, but no significant difference was documented. This finding might suggest that 
metallosis is rather a patient specific factor instead of a result of combining different materials. However, it is acknowledged that this study may be under-powered and future studies involving great numbers of retrievals are important.

Ti fixtures had similar levels of fretting and pitting regardless of whether they were fixed with $\mathrm{CoCr}$ or Ti rods. Black debris on the contact areas of the fixtures were mostly biological, while no transfer from the $\mathrm{CoCr}$ rods to Ti fixtures was observed. Comparing the mean values of corrosion scores between rod junctions and fixtures of the same patient showed that both components were almost equally damaged, revealing no significant difference on the surface damage between the more active metal part and the more noble part of the junction. This suggests that galvanic coupling of the metals in this instance did not accelerate the corrosion process and was rather stable, similar to that suggested by preclinical testing (19).

Up-to-date, most spine retrieval papers used components made of Stainless Steel and Ti alloys $(9,12,18)$, both of which have been used for several years in treating spine deformities. Evidence of corrosion and wear has been documented, including case reports of metallosis which is linked to surface deterioration of the implanted devices (20-24). However, there are more recent suggestions that the physical and mechanical properties of $\mathrm{CoCr}$ rods are more appropriate for the increased correctional forces of the deformed spine than rods made of different material (10). This resulted in the introduction and promotion of $\mathrm{CoCr}$ rods from several manufacturers, especially in the cases of extensive adult deformities. Based on the relevant published research on retrieved hip replacements, there is evidence of increased corrosion in mixed materials, putting the galvanic corrosion into the spot light. The presence or not of this phenomenon needs to be determined, in order to secure the safety of the material combination used in spine surgery. 
This work is the first retrieval study including comparison between similar and dissimilar use of materials on rod-screw junctions, using components made of $\mathrm{CoCr}$ and $\mathrm{Ti}$ alloys. This is a first step towards investigating and determining the in vivo performance of spine instrumentation; future work will involve correlating the material loss and change of surface roughness of the contact areas with the corrosion scores described here. Equally important is the correlation of the junction score in relation to the location at the spine column in order to evaluate whether increased loading results in increased corrosive damage. Finally, the inclusion of more material combinations will offer a better understanding of the processes that are taking place during the implantation of spine instrumentation in the cases of similar or dissimilar material combination.

\section{CONCLUSION}

We have described corrosion scores for the assessment of retrieved spinal implants. Using this score, we found no evidence of increased corrosion when two different materials are galvanically coupled in spine instrumentation. This suggests that metallosis may due more than just implant risk factors, and the impact of the patient and surgeon should be considered.

\section{ACKNOWLEDGEMENTS}

We are grateful for the support of the theatre staff at the Royal National Orthopaedic Hospital, Anna Di Laura, Arianna Cerquiglini, Ilona Swiatkowska and Akramul Hoque for their coordination of the retrieval centre, Dr Tom Gregory, SEM technician, at UCL Archaeology Institute, Mr Amir Amiri, Mr Ali Najefi and Mr Adam Benton for providing patient details and consents. 


\section{REFERENCES}

1. Rajaee $\mathrm{S}$, Kanim L, Bae H. National trends in revision spinal fusion in the USA. Bone Joint J. 2014;96(6):807-16.

2. Kurtz S, Ong K, Lau E, Mowat F, Halpern M. Projections of primary and revision hip and knee arthroplasty in the United States from 2005 to 2030. J Bone Joint Surg Am. 2007;89(4):780-5.

3. Gilbert JL, Jacobs JJ. The mechanical and electrochemical processes associated with taper fretting crevice corrosion: a review. Modularity of orthopedic implants: ASTM International; 1997.

4. Jacobs JJ, Gilbert JL, Urban RM. Current concepts review-corrosion of metal orthopaedic implants. J Bone Joint Surg Am. 1998;80(2):268-82.

5. Oladokun A, Pettersson M, Bryant M, Engqvist $H$, Persson $C$, Hall R, et al. Fretting of CoCrMo and Ti6Al4V alloys in modular prostheses. Tribology-Materials, Surfaces \& Interfaces. 2015;9(4):16573.

6. Goldberg JR, Gilbert JL, Jacobs JJ, Bauer TW, Paprosky W, Leurgans S. A multicenter retrieval study of the taper interfaces of modular hip prostheses. Clinical orthopaedics and related research. 2002;401:149-61.

7. Bryant M, Ward M, Farrar R, Freeman R, Brummitt K, Nolan J, et al. Failure analysis of cemented metal-on-metal total hip replacements from a single centre cohort. Wear. 2013;301(1):22633.

8. Hood RW, Wright TM, Burstein AH. Retrieval analysis of total knee prostheses: a method and its application to 48 total condylar prostheses. Journal of biomedical materials research. 1983;17(5):829-42.

9. Akazawa T, Minami S, Takahashi K, Kotani T, Hanawa T, Moriya H. Corrosion of spinal implants retrieved from patients with scoliosis. Journal of Orthopaedic Science. 2005;10(2):200-5.

10. Serhan H, Mhatre D, Newton P, Giorgio P, Sturm P. Would CoCr rods provide better correctional forces than stainless steel or titanium for rigid scoliosis curves? Clinical Spine Surgery. 2013;26(2):E70-E4.

11. Serhan $H$, Slivka $M$, Albert $T$, Kwak SD. Is galvanic corrosion between titanium alloy and stainless steel spinal implants a clinical concern? The Spine Journal. 2004;4(4):379-87.

12. Vieweg $U$, Van Roost D, Wolf HK, Schyma CA, Schramm J. Corrosion on an internal spinal fixator system. Spine. 1999;24(10):946-51.

13. Kasai $Y$, lida $R$, Uchida $A$. Metal concentrations in the serum and hair of patients with titanium alloy spinal implants. Spine. 2003;28(12):1320-6.

14. del Rio J, Beguiristain J, Duart J. Metal levels in corrosion of spinal implants. European Spine Journal. 2007;16(7):1055-61.

15. Villarraga ML, Cripton PA, Teti SD, Steffey DL, Krisnamuthy S, Albert T, et al. Wear and corrosion in retrieved thoracolumbar posterior internal fixation. Spine. 2006;31(21):2454-62.

16. Kirkpatrick JS, Venugopalan R, Beck P, Lemons J. Corrosion on spinal implants. Journal of spinal disorders \& techniques. 2005;18(3):247-51.

17. Prikryl M, Srivastava S, Viviani G, Ives M, Purdy G. Role of corrosion in Harrington and Luque rods failure. Biomaterials. 1989;10(2):109-17.

18. Wang JC, Warren DY, Sandhu HS, Betts F, Bhuta S, Delamarter RB. Metal debris from titanium spinal implants. Spine. 1999;24(9):899-903.

19. Mali SA, Singh V, Gilbert JL. Effect of mixed alloy combinations on fretting corrosion performance of spinal screw and rod implants. Journal of Biomedical Materials Research Part B: Applied Biomaterials. 2016.

20. Takahashi S, Delecrin J, Passuti N. Intraspinal metallosis causing delayed neurologic symptoms after spinal instrumentation surgery. Spine. 2001; 26(13):1495-8.

21. Tezer M, Juzgun $U$, Hamzaoglu A et al. Intraspinal metalloma resulting in late paraparesis. Arch. Orthopaedic Trauma Surg. 2005; 125(6):417-21. 
22. Gaine WJ, Andrew SM, Chadwick P, et al. Late operative site pain with isola posterior instrumentation requiring implant removal: infection or metal reaction? Spine. 2001; 26(\%):583-7.

23. Goldenberg Y, Tee JW, Salinas- La Rosa CM, Murphy M. Spinal metallosis; a systematic review. Eur. Spine J. 2016; 25(5):1467-73.

24. Senaran $\mathrm{H}$, Atilla $\mathrm{P}$, Kaymaz $\mathrm{F}$, et al. Ultrastructural analysis of metallic debris and tissue reaction around spinal implants in patients with late operative site pain. Spine. 2004; 29(15): 1618-23. 


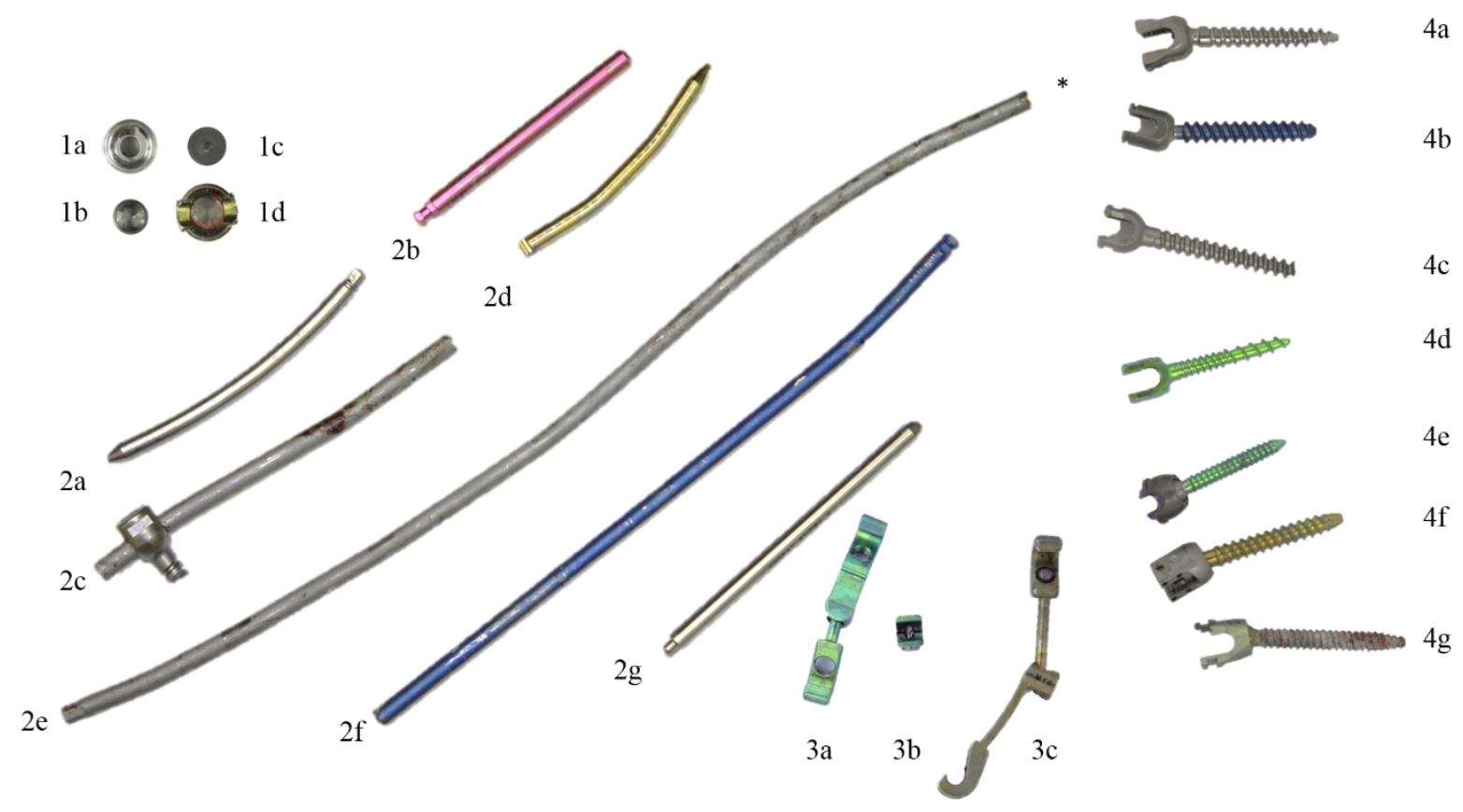

Figure 1. Samples of components used in this study; where components labelled 1a-1d are Ti nuts, 2a$2 \mathrm{~d}, 2 \mathrm{f}$ and $2 \mathrm{~g}$ are Ti rods, $2 \mathrm{e}$ is $\mathrm{CoCr}$ rod, $3 \mathrm{a}-3 \mathrm{c}$ are Ti connectors, and $4 \mathrm{a}-4 \mathrm{~g}$ are Ti screws.

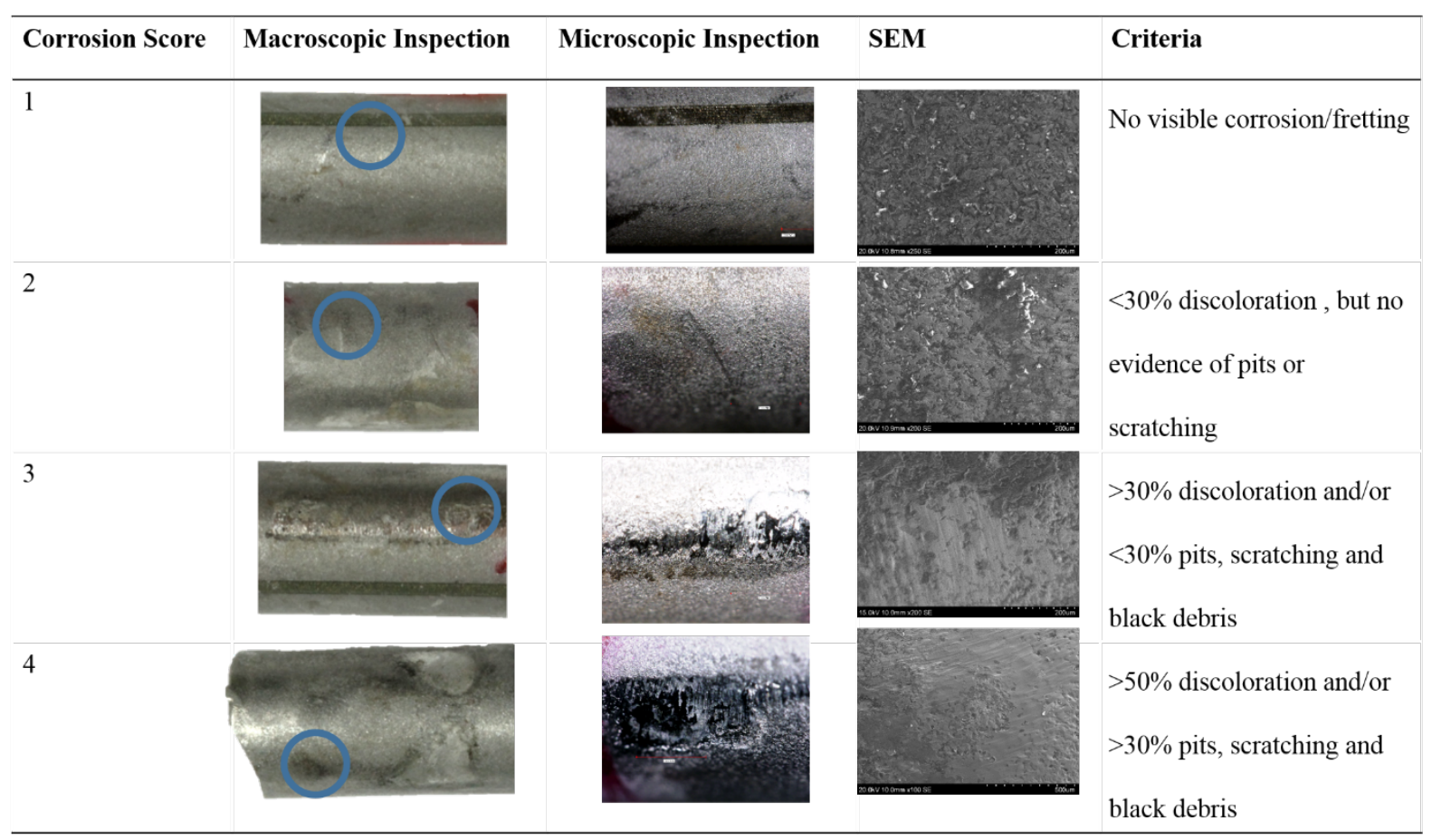

Figure 2. Different grades of the visual scoring of the junctions on the rods, with corrosion score from 1 to 4, under macroscopic inspection (blue circles mark the areas of interest), microscopic inspection of the areas of interest using Optical Microscope and Scanning Electron Microscope (SEM), as scored according to the criteria mentioned. Blue arrows identify the damaged areas with fretting. 


Corrosion Score Macroscopic Inspection Microscopic Inspection SEM No visible corrosion/

Figure 3. Different grades of the visual scoring on the contact areas on the fixtures. Screw with corrosion score 1, showed no signs of fretting during macroscopic inspection, while under the optical microscope and SEM the area of interest (blue circles) showed slight fretting perpendicular to the manufacturing lines. Nuts with corrosion score 2 and 3 presented some circular marks (blue arrows), resulting to discoloration affecting less or more than $30 \%$ of the contact area, respectively. Both optical microscope and SEM confirmed circular fretting, probably during implantation. Connector with corrosion score 4, had signs of black debris, which was confirmed to be of biological origin from Energy Dispersive X-ray Spectroscopy. 


\begin{tabular}{|c|c|c|c|c|c|c|c|}
\hline 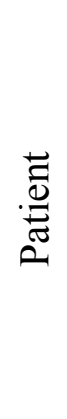 & $\frac{\dot{\theta}}{\overline{0}}$ & 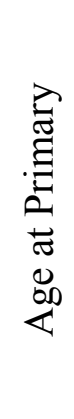 & 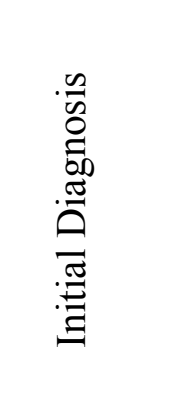 & 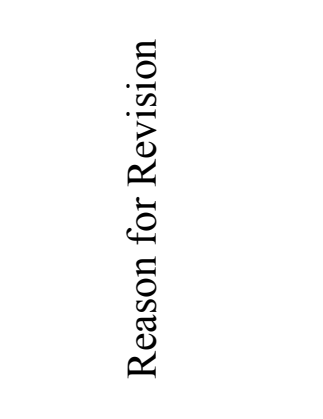 & 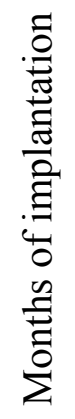 & 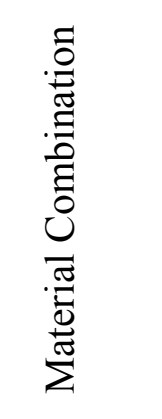 & 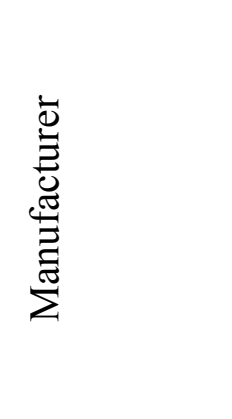 \\
\hline 1 & $\mathrm{~F}$ & 64 & Scoliosis & Infection & 68 & $\mathrm{CoCr} / \mathrm{Ti}$ & $\mathrm{K} 2 \mathrm{M}$ \\
\hline 2 & $\mathrm{~F}$ & 34 & Scoliosis & Unexplained Pain & 28 & $\mathrm{CoCr} / \mathrm{Ti}$ & $\mathrm{K} 2 \mathrm{M}$ \\
\hline 3 & $\mathrm{M}$ & & $\begin{array}{l}\text { Fractured } \\
\text { Vertebra }\end{array}$ & Fractured Screw & & $\mathrm{Ti} / \mathrm{Ti}$ & Stryker \\
\hline 4 & $\mathrm{M}$ & 30 & $\begin{array}{l}\text { Fractured } \\
\text { Vertebra }\end{array}$ & $\begin{array}{l}\text { Correction of } \\
\text { Kyphosis }\end{array}$ & 9 & $\mathrm{Ti} / \mathrm{Ti}$ & $\begin{array}{l}\text { DP Synthes/ } \\
\text { Stryker }\end{array}$ \\
\hline 5 & $\mathrm{~F}$ & 18 & Scoliosis & Infection & 4 & $\mathrm{Ti} / \mathrm{Ti}$ & Medtronic \\
\hline 6 & $\mathrm{~F}$ & 16 & $\begin{array}{l}\text { Fractured } \\
\text { Vertebra }\end{array}$ & $\begin{array}{l}\text { Prevent adjacent } \\
\text { segment } \\
\text { degeneration }\end{array}$ & 16 & $\mathrm{Ti} / \mathrm{Ti}$ & Orthofix \\
\hline 7 & $\mathrm{M}$ & 56 & & Screw Loosening & 5 & $\mathrm{Ti} / \mathrm{Ti}$ & Globus \\
\hline
\end{tabular}

Table 1: Demographic data for the patient cohort, including gender, age at primary, reason for primary and revision surgeries, months of implantation, material combination and implant manufacturer. 


\begin{tabular}{ccccc}
\hline Patient & Number of Rods & $\begin{array}{c}\text { Number of } \\
\text { Fixtures }\end{array}$ & $\begin{array}{c}\text { Number of contact } \\
\text { areas on the rods }\end{array}$ & $\begin{array}{c}\text { Number of contact } \\
\text { areas on the fixtures }\end{array}$ \\
\hline 1 & 2 & 36 & 60 & 36 \\
2 & 2 & 18 & 32 & 18 \\
3 & 2 & 4 & 4 & 4 \\
4 & 4 & 15 & 16 & 15 \\
5 & 2 & 17 & 28 & 17 \\
6 & 2 & 8 & 8 & 8 \\
7 & 1 & 4 & 4 & 4 \\
\hline
\end{tabular}

Table 2. Number of components and contact areas per patient. Different patterns on the rods revealed different contact areas from different components, thus attributing to the large number of contact areas. Retrieved fixtures were less than the contact areas on the rods, common side effects of the increased number of components used in spinal surgery.

\begin{tabular}{ccc}
\hline Visual Score & CoCr/Ti junctions $(\mathrm{n}=92)$ & $\mathrm{Ti} / \mathrm{Ti}$ junctions $(\mathrm{n}=60)$ \\
\hline 1 & $5(5 \%)$ & 0 \\
2 & $42(46 \%)$ & $20(33 \%)$ \\
3 & $41(45 \%)$ & 0 \\
4 & $4(4 \%)$ & $20 \%)$
\end{tabular}

Table 3: Summary of scores for the spinal rods in constructs with similar or dissimilar materials. 


\begin{tabular}{ccc}
\hline Visual Score & $\mathrm{CoCr} / \mathrm{Ti}$ & $\mathrm{Ti} / \mathrm{Ti}$ \\
\hline 1 & $3(6 \%)$ & $6(12 \%)$ \\
3 & $23(44 \%)$ & $19(40 \%)$ \\
4 & $23(44 \%)$ & $23(48 \%)$ \\
& $3(6 \%)$ & 0 \\
\hline Total number of contact areas of retrieved & 52 & 48 \\
fixtures & &
\end{tabular}

Table 4: Summary of scores for the retrieved screws, nuts, hooks and connectors in constructs with similar or dissimilar materials. 


\begin{tabular}{|c|c|c|}
\hline Component & & Mean score \\
\hline \multirow{3}{*}{ Patient 1} & Rod 1 & 2.5 \\
\hline & Rod 2 & 2.3 \\
\hline & Fixtures & 2.5 \\
\hline \multirow{4}{*}{ Patient 2} & Rod 1 & 2.8 \\
\hline & $\operatorname{Rod} 2$ & 2.4 \\
\hline & Fixtures & 2.5 \\
\hline & Rod 1 & 2.0 \\
\hline \multirow[t]{2}{*}{ Patient 3} & Rod 2 & 2.0 \\
\hline & Fixtures & 2.5 \\
\hline \multirow{5}{*}{ Patient 4} & Rod 1 & 2.0 \\
\hline & $\operatorname{Rod} 2$ & 2.0 \\
\hline & Rod 3 & 2.3 \\
\hline & Rod 4 & 2.3 \\
\hline & Fixtures & 1.8 \\
\hline \multirow{3}{*}{ Patient 5} & Rod 1 & 2.3 \\
\hline & Rod 2 & 2.8 \\
\hline & Fixtures & 2.9 \\
\hline \multirow{3}{*}{ Patient 6} & Rod 1 & 2.0 \\
\hline & Rod 2 & 2.0 \\
\hline & Fixtures & 2.1 \\
\hline \multirow[b]{2}{*}{ Patient 7} & Rod 1 & 2.5 \\
\hline & Fixtures & 2.0 \\
\hline
\end{tabular}

Table 5. Mean values of scores per rod and fixtures per patient. 